Brit. J. industr. Med., 1953, 10, 179.

\title{
FROM FACTORY INSPECTION TO ADULT HEALTH SERVICE \\ A REVIEW OF GOVERNMENTAL ADMINISTRATION OF OCCUPATIONAL HEALTH
}

\author{
BY \\ MILTON I. ROEMER* \\ Geneva, Switzerland
}

(RECEIVED FOR PUBLICATION MARCH 28, 1953)

In western Europe, the view seems to be widely held that the protection of the health of workers, by definition and by practical necessity, must be a legal responsibility of ministries or departments of labour. There are good historical reasons for this viewpoint, and considerable practical experience to back it up. In today's world, however, where newly industrializing countries are looking to the west for advice, it is worth examining the assumptions of this principle. Certainly, one does not want to export ideas about social organization and governmental administration which would not apply well in other cultures or, indeed, may not even be properly meeting the current needs of the older industrialized nations themselves.

\section{Historical Development}

The rise of factory inspection in Great Britain in the early nineteenth century, and later on the European continent, was a reaction to the squalor of contemporary industrial production methods. It reflected the growing humanitarian conscience of the day and was the response of government to the demands of working people for a decent life. Naturally, the primary focus was on the protection of the worker-and more especially the woman and child worker-against the harmful effects of the work itself. Occupational diseases, like lead poisoning and "miner's asthma", had been known for some time, and some effort could reasonably be made toward their prevention. The general environment of the factory could be assured, at least, to meet minimum standards of hygiene (Teleky, 1948).

Here and there, benevolent employers made an

* Dr. Roemer was recently Chief of the Section of Social and Occupational Health in the World Health Organization.-ED. effort to provide good working conditions for their workers, independently of legal inducement. These employers, in fact, helped to inspire the enactment of welfare laws. On a wide national scale, however, the police powers of the state had to be invoked, and inspection services had to be developed to compel general compliance with minimum standards. The physical environment of the factory was, of course, only one aspect of the labourer's welfare, of which hours of work, periods of rest, and the status of children and women were others. Departments or divisions of labour welfare were the obvious governmental instrument for exercising this authority to inspect and enforce compliance.

Toward the latter part of the nineteenth century and the early twentieth a new conception entered industrial life, namely, the responsibility of employers for the social consequences of industrial injuries. Behind the first industrial injuries or workmen's compensation acts was a long story of social and legal battle. The eventual effect of the new laws, however, first in Europe and later in the United States, was to induce employers to protect their workers by guarding dangerous machinery, installing safety devices, and introducing various measures to reduce accidents.

The first full-time factory inspectors were appointed under the British Factory Act of 1833, and the pattern spread rapidly. In 1898 the first Medical Inspector of Factories was appointed in recognition of the need for understanding the human reaction to toxic substances, as well as the purely environmental aspects of industrial hygiene. In the United States of America, a few states, in the $1880 \mathrm{~s}$, appointed factory inspectors to enforce labour codes but all the states did not 
have factory inspectors until about 1920; and medical guidance was rarely incorporated in the inspectorate. Whether or not medically guided, factory inspection was obviously oriented toward the removal of specific hazards of the industrial environment which might contribute to occupational diseases or industrial accidents. On the whole, the inspection programmes in Europe were undoubtedly effective; the incidence of occupational diseases and industrial accidents-relative to the increasing numbers of persons engaged in industry-was reduced.

In the early twentieth century, under the influence of factory inspection and workmen's compensation laws, employers came to recognize that productivity could be increased and the workers kept better satisfied by providing some direct medical services at the place of work. Physicians were occasionally appointed for regular service in the larger plants and mines. Such appointments were sometimes related to the need for some general medical care in isolated areas, but more often to the desire of employers to reduce compensation insurance costs by providing prompt first aid and treatment of injuries. Such industrial physicians could also perform medical examinations on job-seekers so as to prevent employment of persons physically unsuitable for the work.

The conception of an industrial health service gradually widened to include not only treatment of injuries and pre-employment medical examination, but also general preventive health services, medical care for minor illnesses occurring on the job, counselling of the worker on all health problems, and supervision of the work environment. The aim came to be adjustment of the man to his job and the job to the man. This approach developed in the larger plants which had financial resources for the service, and was not made a legal requirement. Laws came to be passed requiring the availability in plants of minimal first-aid staff and equipment, but the engagement of full-time medical staffs, specially trained for the purpose, was a matter for private initiative. While this scale of industrial health -service, therefore, has come to cover only a small minority of workers-even in the well developed economies of western Europe and North Americathe theory behind it has taken a firm root in social thinking. In recent years, as we shall see, it has had an impact on health legislation.

This broader conception of health protection of workers is of special importance in relation to the place of supervisory authorities for the workers' health in the structure of government. For, while the theory and practice of industrial health service has been expanding, a similar evolution has taken place in government. The role of public bodies, national and local, in the protection of the health of the general population has gradually broadened. The trend has applied to both preventive and curative medicine. Many governmental agencies are involved in this process, but the most important are the ministries or departments of health in which professional skills in medical-social administration have become increasingly gathered.

It is not surprising, therefore, that as the scope of interest in occupational health has broadened from the narrow sphere of occupational disease and accident prevention to the broad sphere of total health service, public health agencies have been brought closer to the factories and mines. The advantage or disadvantage of this relationship will be considered below, but first it may be helpful to review the current methods of administration of occupational health services in government throughout the world. It may surprise some readers to find that the western European patterns are by no means universal.

In this review, it is helpful to keep in mind a distinction between the supervisory responsibilities of government, and the direct responsibility for clinical preventive or curative services at the place of work. Our focus here is on the former, and this has importance insofar as it may affect the latter. Just as we have seen the influence of private industrial practices on legislation historically, it is obvious that the legislation and methods of governmental administration will shape the content of health services rendered within the factory, mine or other place of work.

\section{Current Governmental Practices in Western Europe}

The basic patterns of factory inspection developing in the early nineteenth century still prevail in the countries of western Europe. This is not to imply that governmental activity has remained static. Far from it ; the scope of the factory inspectors has steadily widened to include all aspects of the working conditions, but the principal objective remains the enforcement of standards designed to prevent occupational diseases and industrial accidents. Beyond this, the medical inspectors of factories are responsible for supervising enforcement of laws regarding medical examinations of certain groups of workers, maintenance of first-aid boxes or factory dispensaries, and other measures designed to protect workers against specific hazards.

In all countries of western Europe special efforts have been made to develop preventive and, to some extent, curative medical services within factories 
even without legislative inducement. As a general rule, these health services have been developed by the larger industries quite independently of the requirements of the factory inspection laws. Occasionally, medical inspectors of factories have participated in the promotion of such services, but usually in a voluntary capacity, as informed professional leaders.

The situation in Norway illustrates the general pattern, although in no two countries are practices exactly alike. The Norwegian Ministry of Labour contains a Directorate of Factory Inspection, first organized in 1892 (Natvig, 1952). It has a staff of seven labour inspectors covering the country on a district basis, three inspectors of special problems, and three medical inspectors. They make periodic inspections of plants to enforce legislation designed to prevent occupational diseases and accidents, the principal current law being the Workers Protection Act of 1936, with amendments. Pre-employment and periodic medical examinations are required for young workers of 15 to 18 years of age, and for workers exposed to silica and to radioactivity. In each of 750 communities there is a local labour inspection committee to help enforce the law. An Institute of Occupational Health is maintained by the Ministry of Labour in Oslo to assist in the diagnosis of occupational disease and to perform relevant laboratory tests (W.H.O., 1952).

Apart from the provisions mentioned, governmental authority is not concerned with the organization of general health services in plants, but a voluntary body has been established for this purpose. This is the Industrial Medical Service Council representing the Norwegian Federation of Labour, the Employers' Association, and the Medical Association. This body sets standards for comprehensive in-plant health services which would include pre-placement and periodic medical examinations of all workers, constant supervision of plant hygiene, first aid and treatment of minor ailments occurring on the job, and referral of workers to personal physicians for diagnosis and treatment of general illness (Bruusgaard, 1952a). There is no compulsion in this programme, and only a small minority of Norwegian workers is covered, but the services are spreading. Cooperation is encouraged with the local public health services in such practices as tuberculosis case finding and reporting, but there is no official connexion with the country's public health framework, national or local.

The other Scandinavian countries have a somewhat similar arrangement. In Sweden, Denmark, and Finland the factory inspectorate is in the Ministry of Social Affairs (rather than a separate
Ministry of Labour), but the functions are essentially the same. In Finland there is an Industrial Medical Association devoted to the voluntary promotion of in-plant medical services, very much as in Norway. Research, training, and specialized services for the detection and control of occupational diseases are given by an independent, but government-supported, Institute of Occupational Health at Helsinki (Noro, 1951). In Sweden a somewhat similar research institute for occupational health is located within the National Institute of Public Health, achieving in this way some coordination with other health research activities (Forssman, 1952).

Practices in Germany reflect the basic approach in central Europe. Being one of the oldest and largest industrialized nations, with a strong tradition of governmental control, Germany has a deeply rooted system of factory inspection. In each German state there is a department of labour which contains a factory inspectorate, divided into a medical branch and an engineering branch. The engineering branch enforces regulations on environmental standards in the factories. The medical branch is staffed by "state industrial physicians" whose main duties are to determine if illness is of occupational origin, and, therefore, entitled to workmen's compensation, and the degree of disability, to act as medical consultant on the treatment of occupational disease cases, to help enforce regulations on the prevention of occupational diseases, and to advise the engineering branch on environmental controls. Tabershaw (1951) has observed that " none of the state industrial physicians have any concept that their functions embrace interest in non-occupational disease, in the total health of the worker or in furthering general public health ". Health services developed in some of the larger plants are devoted to giving medical examinations to certain workers exposed to special risks and first aid for occupational injuries and other minor ailments. There is little tendency to go beyond the minimum requirements of the law.

The detailed specifications of the classical factory inspection systems of each European country need not be reviewed. A complicated legal structure has grown up over the years, establishing minimum precautions which must be taken by industry to prevent accidents and certain specified occupational diseases. There are also requirements for first-aid services and supplies which must be available in the plants, for general toilet and washing facilities, for the use of safety devices, and for basic standards of space, lighting, ventilation, etc. The enforcement of these regulations is the duty of the factory 
inspectorate. With minor exceptions, there is no connexion between the factory inspectorate and the general public health programme of the region.

The relatively narrow scope of the factory inspection approach has been realized in Europe for some years, especially since occupational accidents and diseases have been reduced. It took the social upheaval of the second world war, however, to cause a major extension in its scope particularly in the French-speaking countries where the upheavals of war and foreign occupation were so great. This is seen best perhaps in the introduction in Belgium and France of the requirement of a general medical examination of all workers before employment. Largely through the practical demonstrations of health programmes in big industrial undertakings, the concept grew that it was to the common benefit of the industry and the worker not only to prevent accidents and industrial intoxications, but also to assure that a worker was physically and mentally suited to a particular job, a principle commonly applied to young workers and to women for some years.

The Belgian law of 1945 requires that each undertaking is responsible for a medical examination of every worker before employment at the expense of the employer. The examinations are performed by any practitioner chosen by the worker, according to a prescribed form. A radiograph of the chest must be included, and may be performed by the National Institute for the Control of Tuberculosis (a semiautonomous organization working closely with the Ministry of Public Health and Families) or by a qualified private physician. The physicians of the factory inspectorate limit themselves to seeing that the examinations are made. The declared purpose of the procedure is not only to assure suitable job placement but also " to inform workers concerning any disorder or deficiency from which they may be suffering and to indicate institutions which can facilitate treatment" (W.H.O., 1951).

This wider protection of the worker's health under the ministries of labour is seen more strikingly in France. After a conventional factory medical inspection system which had operated since 1915, France enacted in October, 1946, the most farreaching legislation of any western European country. For the first time in a western European country, the provision of a systematic medical service in every factory, regardless of size, was made compulsory (Bousser and Gillon, 1952). This service must provide not merely pre-employment medical examinations of all workers but annual re-examinations, and more frequent re-examinaticns of young persons and workers exposed to special hazards. Annual chest radiographs of all workers are required. Emphasis is placed on proper job placement of the individual according to his particular capabilities, rather than exclusion of the unfit. First aid and diagnosis of any illness is provided in the plant, but for medical care the worker is referred to a personal physician. These services are to be rendered by part-time or full-time physicians engaged by the employer. The law specifies one medical hour per month for about every 15 workers (less for white-collar workers and more for workers under special risk), so that a full-time industrial physician is required for about every 2,250 workers.

This programme is supervised by the Medical Inspectorate of Labour and Manpower of the French Ministry of Labour and Social Security. The 14 regional medical officers of this agency must approve of the medical arrangements made by all employers in their region, and it is their duty to help to organize the services required by the 1946 law. They promote the grouping of small plants which, together, can engage the full-time services of a physician. They also carry out the usual duties of medical inspectors of factories in other countries, such as examination of specific cases of occupational disease for compensation claims, evaluation of environmental hazards, and enforcement - with the general factory inspectors - of regulations. Up to the present time, the new industrial medical service is far trom complete, but progress is rapid. By January, 1950, approximately $50 \%$ of the workers, covered by the legislation, were being provided with medical services through programmes in 2,411 companies and 522 inter-company groups. The inspection staff has been unable to keep up with the task of reviewing and approving these services. There is no connexion with the public health services except in special instances, such as the impressive coordinated programme at Nancy, or the arrangement at Toulouse for nurses from the public health staff to serve in a local factory.

In all European countries, the organization of preventive services in the plants is, of course, influenced by the laws providing financial compensation to workers for industrial injuries and diseases. Large insurance companies may even provide this protection, as they naturally have a financial interest in keeping the accident rate at a minimum. In Italy, for example, there is a National Organization for Accident Prevention which not only conducts general educational campaigns, but actually operates medical clinics in the large plants, providing first-aid and minor medical services (Canaperia, 1950). The compensation laws have had the salutary effect of inducing employers to prevent accidents or reduce 
disability resulting from them. At the same time, however, they have tended to concentrate action so much on compensatable conditions that too little attention has been given to the larger health problems of the worker.

Discussion of industrial health services in Great Britain has been delayed because, in the current debates and self-examination of the problem in that country, there are reflected some of the fundamental organizational problems that may eventually be encountered by all countries. With the organization of the British National Health Service, bringing virtually all health care, curative and preventive, under government control, authorities were faced with questions of administrative efficiency and with the necessity to spend the available health funds with maximum effectiveness.

As in continental Europe, factory inspection under the Ministry of Labour and National Service is focused primarily on the prevention of occupational diseases and accidents. There are some 15 regional medical inspectors of factories who are experts in the investigation of occupational disease and related environmental hazards. Spread throughout the country are some 1,700 appointed factory doctors-almost all part-time general practitionerswhose duty is to make medical examinations of young workers and workers exposed to special risks, and to investigate cases of occupational disease which are notifiable. The appointed factory doctors are paid by employers on the basis of the number of examinations they make, but they are administratively responsible to the medical inspectors of factories. There are approximately 1,300 full-time and part-time industrial medical officers, employed by private and nationalized industries for general in-plant health services. They are assisted by about 4,000 industrial nurses of whom about 2,600 are State Registered. The in-plant health services as in other countries are principally in the larger plants, except for a few special cooperative projects, like the Slough Industrial Health Service near London (Dale Report, 1951).

With the pressure on medical man-power under the National Health Service, and with the complexities of comprehensive health administration, many questions have been raised about the soundness of this general system. In 1949 a Committee of Enquiry on Industrial Health Services was appointed by the Prime Minister, under the chairmanship of Mr. Justice Dale. This report (known as the Dale Report, 1951) concluded that industrial health services of a preventive nature were valuable, that they were not available under the National Health Service, and that present patterns should be con- tinued substantially without change. Reaction to these conclusions from many quarters was coolnot because there was lack of appreciation of the positive value of a good industrial health service, but rather because there was widespread feeling of a need for some closer administrative coordination with the National Health Service. Debate on this question has been active. In a symposium held at the Royal Sanitary Institute Congress in 1952 several new approaches were suggested. That receiving most attention was made by I. G. Davies (Davies, Schilling, and Banks, 1952). He suggested that supervisory responsibility for industrial health services at the community level should be under the local medical officer of health, who would be aided in carrying out these duties by the appointed factory doctors. Technical advice anc consultation on the complex problems of occupational diseases would remain the responsibility of the regional medical inspectors of factories. Thus, at the higher levels, the Ministry of Labour and National Service would retain its responsibilities, but at the community level-where health service has its direct impact on people-the Ministry of Health could exercise appropriate supervision and integration of industrial health service with the total health programme

The debate and the proposals in Great Britain have particular significance internationally, because they are the first, or at least the major, instance in western Europe in which the separation of the factory inspection system from the public health framework of a country has been challenged. This basic issue of relationships between labour and health ministries in the supervision of the worker's health is latent in almost all countries, and it has become sharper as the scope and dignity of public health organization has increased. In the rest of the world, outside of western Europe, the respective responsibilities of these two agencies of government are much more fluid, and consequently the pattern of administration of occupational health supervision is taking different shapes.

\section{North America}

As in many aspects of social welfare, the assumption of governmental responsibility for the worker's health came later in the United States than in Europe. Virtually all responsibilities for health and welfare belonged to the States, and supervision of the conditions in factories by an inspection system was not started until the end of the nineteenth century. New Jersey and Wisconsin were the pioneers in 1883. Factory inspection programmes in state departments of labour developed slowly in the early 
twentieth century, modelled after the European practices, but in the American climate of laissez-faire liberalism with minimum government control, they were not very strong. The inspectors were rarely trained in engineering or chemistry or other appropriate fields. In only one state was medical guidance sought, in New York State, where in 1907 a single medical inspector of factories was appointed, but the idea did not spread.

There was obviously a gap to be filled in the development of a scientific programme of industrial hygiene which could tackle both the environmental and the medical aspects of occupational diseases. In 1914, the United States Public Health Service attempted to fill this gap by establishing the Office of Industrial Hygiene and Sanitation, primarily for research purposes. Similar research activities were undertaken in the Departments of Labour of New York and Ohio, but on the whole the State and local public health agencies were not strong enough to do this work. As in Europe, here and there private industry developed preventive and, more often, curative programmes, especially in isolated areas and in large plants. The first world war gave this practice an impetus in the interest of preserving effective man-power. The workmen's compensation laws, which were initiated only after 1911, had the same effect-in the interest of reducing insurance rates. Then came the depression in 1929, and in 1935 a new opportunity was presented to the nation's public health agencies with the passage of the Social Security Act (Klem, McKiever and Lear, 1950).

Under this law larger funds were made available for public health services than ever before through the device of federal grants-in-aid to the States. The Public Health Service administered these grants and, having now had 20 years of experience in industrial health research, it used them to help the States develop industrial hygiene units in the State departments of health. The idea grew rapidly, so that today every state public health agency, except four, and several large city health departments contain specialized staffs for promoting the health protection of workers.

The functions of these public health units in industrial hygiene are very different from those of factory inspectorates. They are not inspecting agencies engaged in the enforcement of laws. They are primarily advisory technical bodies, devoted to the promotion within their states of sound hygienic practices within industry. It is not that they lack enforcement powers, as is sometimes believed, for all public health agencies have general powers to require correction of hazards to health (Trasko, 1950). It is rather that, in the American culture, health authorities are convinced they can achieve better long-term results by a process of education, demonstration, and persuasion than by the enforcement of laws. While the effectiveness of these industrial hygiene units differs markedly among the States, they have developed a nation-wide network of consultant services which has helped to reduce the incidence of occupational diseases to an extremely low level.

These developments have a far greater significance, however, than the integration of industrial hygiene services in the American public health system. An opportunity has been provided for bringing to bear the broad field of preventive health services, embodied in the modern public health movement, upon the workers in industry. The need of industry and the community as a whole is a healthy worker, and not merely a worker free from occupational poisoning or injury. The importance of this has become increasingly recognized as studies of sickness absenteeism in the United States have shown that, on the average, only about 5 or $6 \%$ of sickness absenteeism can be traced directly to conditions arising from work (Newquist, 1938). The over-' whelming bulk of illness relates to non-occupational causes. Its reduction, therefore, not to mention the achievement of health, calls for a generalized health programme, such as can be promoted by the community public health agency. This concept was stated clearly several years ago by Bloomfield (1938).

\footnotetext{
" It would seem, therefore, that if we are to improve the general health status of the most important and numerous group in our population, it will be necessary to control not only unhealthful conditions in the working environment, but also to give consideration to such factors as proper living conditions, nutrition, elimination of strain and hurry, communicable diseases-in fact, a general adult health program for all workers. In order to promote a broad and effective industrial health program of this type, it will be necessary to integrate it closely with existing public health activities."
}

Under the wing of the public health agency, industrial health responsibilities of government in America are increasingly taking the form of an "adult health service". The factory is being used as a channel through which general public health programmes are promoted, very much as the schools are a channel for protection of the general health of children. Services are rendered for workers in the control of tuberculosis and venereal disease, immunization against infectious diseases, nutrition, general health education, detection of chronic disorders, environmental sanitation, mental hygiene, dental care, maternal and child health, and medical rehabilitation. Beyond this, industry is encouraged 
to develop systematic in-plant services (Roemer, 1948). Not that this ideal integration is achieved everywhere, but this is the direction for which the framework has been laid. Health departments still have a long way to go in persuading industry to provide regular in-plant health service programmes, especially in small plants (Miller, 1952).

As might be expected, there has been some dispute between labour and public health agencies in the United States, particularly in the investigation of environmental hazards contributing to occupational diseases. The agreement, in general, however, has been for the factory inspection services to concentrate mainly on accident prevention, while the public health industrial hygiene units deal with the risks of occupational disease and the promotion of general preventive medical services in the plants. When legal action must be taken to enforce correction of an environmental hazard, it is usually, though not always, handled by the Labour Department. In some states, like California, very close working relationships have developed between the labour and health agencies, under which each not only respects the jurisdiction of the other, but also agrees actively to advance the programme of the other by consultation and by referring problems to each other (California State Department of Health, 1952).

In Canada, essentially the same pattern is found as in the United States, with even more authority for the protection of workers against unhygienic working conditions vested in provincial departments of public health (I.L.O., 1951). Factory inspection is conducted by the provincial departments of labour or their counterparts, but regulations regarding specific industrial health hazards, including compulsory periodic medical examinations, are issued by provincial ministers of health. In the Dominion Ministry of National Health and Welfare and in each provincial department of health, there are industrial hygiene divisions which investigate occupational health problems and actively promote the organization of general health services at working places.

\section{South America}

Industrialization in South America is relatively recent and legislation protecting labour did not begin to be passed until well into the twentieth century. The dominant pattern originally was exclusive responsibility for industrial health service in the national labour agencies following the patterns of European nations (Spain, Portugal, and France) with which Latin America was culturally tied. With the "good neighbour" policy of
President Roosevelt, the influence of the United States grew, and since about 1940 increasing responsibility for occupational health administration has been assigned to the public health authorities.

In Brazil, the Ministry of Labour, Industry, and Commerce has a Division of Industrial Hygiene and Safety, which engages some 25 physicians. These men investigate occupational health hazards, and they also perform medical examinations of workers in certain plants. Owners of large plants (over 500 workers) in isolated places are obliged by law to provide their own medical staff for emergency medical care. The National Department of Health in Brazil has had no official responsibilities in occupational health, except that its training institute includes a three-month course for doctors in industrial hygiene. Plans are under way, however, to organize an industrial health unit in the National Department of Health which would emphasize preventive services (Bloomfield, 1950).

The Argentine, the second largest country in South America, places a great deal of responsibility for occupational health in its health agencies. The Ministry of Public Health has an Office of Industrial Medicine which advises employers and trade unions on industrial health problems (Escarra, 1952). Physicians in this office also examine workers to determine the degree of disability of industrial injuries, a task done on behalf of the National Social Welfare Institute which administers the social security programme. The Ministry of Labour has a Bureau of Occupational Hygiene and Safety which, on the request of trade unions, investigates hazardous conditions and can compel correction, but it does not carry out routine or systematic factory inspection. The Health Ministry's Office of Industrial Medicine also conducts such surveys and advises employers generally on hygienic practices. In addition, it offers training courses for physicians and engineers in occupational health. At the provincial level, little is done in governmental industrial hygiene, except in Santa Fé province where the Health Department contains an active Division of Occupational Hygiene and Safety.

The dispersion of authorities for various aspects of industrial hygiene among different ministries is a feature of several countries in South America. The situation in .Chile has been summarized by Bloomfield (1948).

\footnotetext{
"The Ministry of Labour has the right to maintain an Industrial Hygiene Section within its Department of Labour, while the Ministry of Health has authorization for a Department of Industrial Hygiene in the National Department of Health. The Bureau of Labour Accidents is empowered to carry on an advisory industrial hygiene and safety programme
} 
among its insured. The Worker's Compulsory Insurance Fund, through its Institute of Labour Medicine, also functions in this field. The Department of Mines and Petroleum has responsibility for the health and safety of workers in mining and allied industries. And, finally, even the municipalities have broad authority in many phases of industrial hygiene."

This dispersion of responsibilities is, above all, a sign of influences to broaden the scope of occupational health service. In the 1930 s many social welfare measures were introduced in Chile. As a feature of its social security programme, Chile was among the first nations to require a periodic medical examination of all workers, under the "Preventive Medicine Law" of 1938. These examinations are designed mainly to detect tuberculosis, syphilis, and heart disease and, while they are administered by the social security authorities, they obviously advance the occupational health programme. In 1952, Chile enacted one of the most significant health laws not only in South America but in the world, its Medical Fusion Act. This sets up a National Health Service in which all governmental health services, including industrial hygiene and the medical provisions of social security, are brought under the unified direction of the Ministry of Health. They are to be administered regionally by Public Health Officers, who will be responsible for all categories of health service in their regions.

Predominant responsibility for supervizing industrial hygiene in Mexico, Peru, Bolivia, and Colombia has rested with the Ministries of Labour, but under the influence of the health programme of the Institute of Inter-American Affairs changes are occurring. The primary emphasis of labour agency administration has often been to assure first aid and medical care following injury, rather than the provision of general preventive health services. Administration of the social security laws providing disability payments, and especially compensation for industrial injuries, have occupied major attention. The cooperative Servicios developed between the Ministries of Health and the Institute of InterAmerican Affairs (I.I.A.A.), however, have begun to organize industrial hygiene divisions with a broad orientation. These divisions, which will eventually be absorbed in the health ministries, promote activities for the prevention of both accidents and occupational diseases, as well as general programmes of tuberculosis and venereal disease control, nutrition, immunizations, health education, and general community sanitation in and around factories. Such activities have been expanding particularly in Peru and Colombia. They are in planning stages in Mexico and Venezuela. In Bolivia, similar programmes are being developed by the I.I.A.A. even with the Ministry of Labour (Bloomfield, 1952).

In South America, as elsewhere, the most advanced work is often done by private industry, especially in isolated areas where the law requires the employer to organize health services. In some of the isolated mines of the Andes there is no community organization whatever for health purposes except that which the company can provide (Diaz, 1951). In this type of situation, occupational health service becomes synonymous with total public health and medical care. There is always a danger of paternalism in activities of this type in the " company town", which the workers dislike. In order to avoid this tendency and to win the support of the workers, the law in Brazil and Mexico requires formation of joint labour-management committees on safety and health. Encouragement of such committees is the policy of the Institute of Inter-American Affairs.

On the whole in South America, there is a distinct tendency toward increasing participation of public health agencies in the supervision of the health of workers. With this trend, there is a broadening of the scope of an industrial health service from concentration on accident prevention and treatment of compensatable disabilities toward an overall preventive health service, complemented by medical care for general illness.

\section{Southern Asia and Africa}

In Egypt a law was passed in 1904 requiring permits for the opening of "objectionable, unhealthy, and dangerous establishments". It was administered by a Department of Permits with a large staff of inspectors for investigating the physical aspects of all industrial installations. This department was placed in various ministries at different times, and in 1948, as the country's public health programme was gaining strength, it was incorporated into the Ministry of Health. In 1939, a Ministry of Social Affairs was established and within it a Department of Labour. In 1944 this Department was given responsibility for routine inspection of factories to detect health hazards. Recently it engaged three full-time doctors and a small staff of sanitary inspectors in order to develop a programme to prevent occupational disease. Meanwhile the Department of Permits in the Health Ministry, with a much larger field staff, does similar work (Bruusgaard, 1952b).

As in most economically under-developed countries, the great problem in Egypt is the hygienic conditions in thousands of very small shops. Employers of 100 workers or more are required to 
provide first aid and minor medical services at the plant, a responsibility usually dispatched by maintenance of a small dispensary staffed by a male attendant with occasional visits by a physician. To supervize health conditions in the small shops, however, a large field staff is required, keeping in close touch with rapidly changing situations. The public health staff of some 700 physicians, engineers, and sanitary inspectors distributed in regional teams throughout Egypt could provide a skeletal framework for doing this task, if some special training were provided and skilled consultant services were available. Industrial accident rates are high, but by far the greatest health problems of the Egyptian worker are the endemic diseases arising from his total living environment-problems for the public health authorities.

In the other Arab countries, governmental activity in industrial hygiene is extremely limited. In Iran, for example, there are labour laws regarding child labour, hours of work, pre-employment medical examinations, working conditions, etc., administered by the Ministry of Labour, but they are not well enforced. The Ministry of Health has been developing interest in the field, as reflected by a recent request for advice from this Ministry to the World Health Organization for technical assistance in the formulation of an occupational health programme. Actually the most effective supervision at the present time is given by a semi-autonomous insurance society, the Worker's Aid Fund. Under the influence of this agency, which handles social security activities, the larger industries provide a limited dispensary service for first aid and minor medical care, usually given by a medical aide (Lewis, 1952).

A somewhat similar situation is found in Turkey, where the most effective controls over health services in industry are rendered by an independent insurance fund, the Worker's Insurance Institute. Legislation in Turkey, since 1930, actually calls upon the Ministry of Health to inspect work places for hygienic conditions and to enforce certain standards. Among these is the requirement that employers of 100 workers or more provide certain in-plant medical services, and that in plants of over 500 workers hospital beds be provided. Turkey is so predominantly agricultural, however, and the limited resources of the public health authorities had to be spread so thinly over vast rural regions, that little attention could be given to the health problems of industry. In 1941, regulations on hygienic conditions in factories were issued by the Ministry of Health and the Ministry of Economics, but enforcement was meagre. Then in 1946 an act was passed providing compensation for industrial accidents and occupational diseases, and giving maternity leave. This was made the responsibility of a newly organized Worker's Insurance Institute, under the general supervision of the Ministry of Labour which had been set up in 1945 . The Institute collects insurance funds and exercises considerable authority over health conditions in factories and mines with insured workers. Employers who pay insurance premiums are exempted from providing the medical facilities required under the 1930 law, since the Worker's Insurance Institute is now supposed to provide these services instead (Petrie, 1952). A factory inspection system was also recently established under the Ministry of Labour.

The establishment of independent institutes, with power to collect money and to spend it, is a common approach to achieving stability for a welfare programme in countries where government is subject to rapidly changing fortunes. This device has the effect, however, of setting up a state within a state, and actually weakening the hand of government by depriving it of funds and responsibilities. As industrialization develops in Turkey, the workers in the cities are becoming unionized and make increasing demands for welfare services. These demands are surely sound, but the way that government responds to them, in these relatively early stages of industrialization, will shape the pattern of all health administration in years ahead.

In the colonial countries of Africa, little is done by government in occupational health supervision which is equivalent to the practices in industrialized countries. The private plantations or estates may, however, provide medical services for their workers and follow basic hygienic practices on housing, sanitation, etc., in fulfilment of the requirements of government charters. Regulations on hygienic standards in labour camps may be issued by the Medical Directorate, as in Nigeria (1950). Occasional surveys of the health of workers may be made by the health authorities, like the $x$-ray studies for silicosis in the mines of the Belgian Congo (1950). Factory inspectorates do not exist and any inspection is a responsibility of the medical department in the colonial government.

In the Union of South Africa factory inspection is organized under the Ministry of Labour and the public health agencies have few responsibilities in the industrial sphere (Cluver, 1948). In India there is likewise a factory inspectorate under the Ministry of Labour, but, by force of circumstances, the public health authorities have become involved in the supervision of hygienic conditions in plants.

There is a great shortage of factory inspectors in 
India and working conditions in some industries are primitive. There is a medical inspector of factories in the Ministry of Labour at New Delhi, but in most provinces the practice has developed of appointing the public health officers as "ex officio factory inspectors" giving them the right to enter plants and to recommend to the Chief Inspector of Factories the enforcement of corrective measures. The regular factory inspectors look to the Health Officer for guidance and assistance on hygienic questions. It is interesting to observe that this arrangement did not appeal to a foreign industrial medicine authority whose advice was sought in 1946. The Annual Report of the Public Health Commissioner with the Government of India (1946) states that this consultant: " has questioned whether the medical inspection of the factories should be left in the hands of public health officers or whether it should be done by medical men serving under the Chief Inspector of Factories, as in Great Britain. The Committee adopted a note on the desirability of instituting a Medical Inspectorate of Mines and Factories in India ". This illustrates well the influence of the older nations, in spite of the efforts of more recently industrialized countries to adjust administrative patterns to local resources and needs.

Some large establishments in India, like the Tata Industries, have set up their own occupational health and medical care programmes which go beyond the requirements of law. As elsewhere in the world, such enlightened managements have advanced the general recognition of needs for occupational health services (Dastur, 1952). The training of medical specialists is being met in some degree by courses at the All-India Institute of Hygiene and Tropical Medicine, under the Ministry of Health. It is significant perhaps that in many countries, where administrative responsibilities rest with labour authorities, training in occupational health is offered by the health authorities. If nothing else, this would indicate the basic identity of industrial medicine with the other fields of social medicine and public health, for which health ministries are responsible.

\section{Western Pacific Region}

The industrialization of Japan since 1860 has been associated with the development of a factory inspection system in the Ministry of Labour. The public health authorities have confined their activities to the control of communicable diseases, environmental sanitation, and other traditional spheres. A remarkable network of over 700 health centres for general preventive services has been developed in Japan in the last few years, but their functions do not, as yet, include health supervision of work places (Japanese Ministry of Health and Welfare, 1951). In 1947, Japan enacted a law requiring pre-employment medical examinations of all workers, reflecting a broadening approach to occupational health.

In Australia, industrial hygiene has been developed as a function of the public health agencies. Health services are organized under each of the six state governments, and each state health department . contains a division of industrial hygiene. There is also a factory inspection system under the state departments of labour, to which the industrial hygiene divisions are advisory on technical health questions. In addition, these divisions conduct industrial health surveys, give direct advice to industry on the correction of hazards, operate clinics for occupational diseases, and promote the organization of generalized in-plant health services. At the Commonwealth level, in the School of Public Health at the University of Sydney, there is an Industrial Hygiene Unit, with training, research, and advisory functions. In Queensland, the Department of Health and Home Affairs is responsible for overall factory inspection, as well as technical services in industrial hygiene (Cummings, Smith, and Hadley, 1952).

The governmental pattern in New Zealand is similar. Factory inspection and enforcement of standards are carried out under the Department of Labour and Employment, but the health aspects of industry are supervized by the Department of Health. There are four regional medical officers for industrial hygiene, who advise on health hazards and promote medical service organization in the plants. They are assisted by nurses, who help to set up industrial nursing programmes. The regional staff work closely with the factory inspectorate, the local public health officers, and the part-time industrial physicians. They also conduct research into toxic processes, and they train physicians and sanitary inspectors in occupational health (Brown, 1950).

Practices in Indonesia illustrate the approach to occupational health of a nation which has been overwhelmingly agricultural and has only recently gained its independence in governmental affairs. Faced with enormous problems of disease and with dire lack of medical personnel and facilities, the new government is setting out to develop an integrated health service, based on health centres from which both preventive and curative services are given. Among the functions of the public health staff at all levels is the supervision of factory hygiene. 
Leimena (1952) regards this as a component part of the sanitary control of the environment. Substantially the same practice is followed in the Philippine Republic (1952) where sanitary inspection of factories and advice in the correction of occupational disease hazards is a function of the Department of Health.

The Hawaiian Islands, being a territory of the United States, naturally adopt the American pattern of having an Industrial Hygiene Division in the Board of Health. This Division investigates occupational disease hazards and advises on their correction ; it receives reports of cases of occupational disease coming before the Workmen's Compensation Division, a practice carried out in many American states. Hawaii is primarily agricultural and a dominant feature of the economy is the large sugar or pineapple plantation. For many years, workers and their families on these plantations have received medical care through a system of salaried physicians and nurses giving complete services, preventive and curative. Since these enterprises have been unionized, the medical programmes, formerly operated entirely by management, are now jointly controlled through collective bargaining (Doyle, 1951; Patterson, 1950).

In colonial or formerly colonial countries generally, plantation medical systems are a major source of health service, preventive and curative, for the agricultural population. It is customary for these programmes to come under some surveillance from the Ministry of Health, especially when the law requires that growers provide certain minimum services. This is so in countries like Ceylon or Malaya with their large tea or rubber estates. The health problems of agricultural production are, of course, very different from those in factories, but these programmes are, nevertheless, providing occupational health services in a rural setting. Supervision by public health authorities permits the country-wide application of uniform standards, which are especially important for the control of communicable diseases in tropical areas.

\section{Northern Asia and Eastern Europe}

An important event in the development of health services in the Union of Soviet Socialist Republics was the institution of a complete system of public medical services. Health protection of workers is a function of the Ministry or Commissariat of Health, carried out as part of the general system of state-supervised curative and preventive services.

Since 1933 the Commissariat of Health has contained an Office of Safety and Hygiene responsible for factory inspection. Engineers are in charge of this work, checking on all new installations and enforcing standards of ventilation, lighting, and so on. This environmental control is coordinated with the system of industrial medical services by the regional public health officer. In all plants there is a medical clinic of some type, connected administratively with the regional system of polyclinics and hospitals for the general population. When a plant has 1,000 workers or more, one or more fulltime physicians are employed ; for smaller plants a nurse is engaged. Any medical care needed is given within the resources of the clinic, whether the illness is of occupational origin or not ; where necessary the patient is referred to a regional health centre or hospital. Since the whole system is supervised by the public health officer, general preventive services are applied to the workers through the factory. The entire medical and safety system is controlled, within each plant containing 50 workers or more, by a Committee for Protection of Work, representing the workers. Problems of occupational disease are tackled through research and consultant service given by a network of some forty institutes of labour hygiene, under the national public health system (Travail et Securité, Paris, 1950; Sigerist, 1947).

The countries of eastern Europe, coming under the same social system have gradually adopted a similar framework for protecting the health of workers. In 1951, Czechoslovakia reorganized all its health services, formerly dispersed among several governmental and voluntary agencies, under the Ministry of Health. In Yugoslavia, the unified pattern is substantially followed. Each of the component republics has a Department of Health in which one or more physicians serve as "sanitary inspectors for industrial hygiene". There are also labour inspectors who enforce the general welfare provisions in industry, but the public health authorities are responsible for the prevention of occupational diseases, special supervision of apprentices and women workers, and surveillance over medical services in the plants. The workers receive all types of medical care through the factory clinics or ambulanta which are financed by the government as part of the general public medical system. A large factory will have its own clinic, while a group of small factories may be served jointly by one. These clinics provide pre-employment examinations and other preventive work, but they have not yet developed skills at job-placement evaluations. Extra services like dental care, not provided in the state programme, may be given at the initiative and expense of the individual factory (Goldwater, 1952).

In China, since 1949, there has been an intensifi- 
cation of health services for industrial workers. Previously, all health questions relating to industry were the responsibility of labour authorities. Today each industry is required to provide certain health services for the workers, according to standards set by the Ministry of Health. General medical services for all conditions are given through the plant clinic (Chu, 1952, personal communication).

\section{Summary}

While this review of the structure of governmental activities in occupational health throughout the world is by no means complete, it may be adequate to demonstrate that widely differing patterns are found, and that the system commonplace in western Europe is by no means universal. Such a statement could not have been made before about 1930, but in the last 25 years a marked change has occurred in the scope and objectives of occupational health work. In western Europe, where a century of experience has crystallized certain patterns of public administration rather rigidly, this broadening viewpoint has expressed itself differently from other countries, where the whole structure of social services has been more fluid.

The focus of labour authorities on the prevention of occupational diseases and industrial accidents has played an invaluable role historically, but it fails to meet current needs. The restrictions of this focus, in relation to total sickness absenteeism, have been mentioned. Further deficiencies are illustrated in the customary requirements for notification of occupational diseases under labour regulations. Such notification is usually tied to the requirements of workmen's compensation legislation, which tend to lag considerably behind the changing hazards of modern industry. From the health viewpoint, any ailment that is conceivably related to working conditions, and hence preventable, should be notifiable. Again, the limitation of pre-employment examinations in so many labour codes to young persons and workers exposed to special risks may satisfy certain welfare conceptions, but it fails to recognize that the prevalence of serious, chronic disease-while not compensatable-is progressively greater in the older worker.

The broadening viewpoint in occupational health can be simply described. It has become increasingly recognized that the protection of the worker's health, both for his sake personally and for the sake of economic productivity, requires concern for his total health and for his physical and mental adaptability to his job. This is a great extension beyond the earlier objectives of avoiding occupational diseases and accidents. The latter purposes remain important and, indeed, call for the application of a vast body of technical knowledge but-considering the total health needs of the worker-they encompass only a small fraction of the problem. The size of this fraction will, of course, vary in different industries and in different countries. Mining in siliceous rock, in a country where preventive measures for the control of silicosis are inadequate, will obviously yield a higher proportionate burden of occupational disease and injury than work in a country where vigorous preventive measures are being enforced or in an industry with fewer inherent hazards. Taking industry as a whole, however, it has probably always been true that purely occupational disease and accident constitutes only a minority fraction of the worker's burden of ill-health, albeit a preventable fraction. As preventive measures are instituted this fraction obviously becomes smaller, so that in the economically advanced countries-despite the increased exposure of man to chemicals and machines - the fraction of human disability caused by direct occupational influences drops to only one-tenth or one-twentieth of the total.

The occupational hygienist of the old school, one might say, has been working himself out of a job, in the same way as does the tropical hygienist who has wiped out malaria. But a job remains, if he widens his horizon to encompass the general health needs of the worker. In practical terms, this widening has occurred in stages. A first stage is related to the attainment of industrial efficiency, and a second stage to the achievement of general community health and well-being. In the former stage, the pre-employment and then the preplacement medical examination is introduced. An effort is made to fit the worker to the job and, likewise, through environmental controls, to fit the job to the worker. In the latter stage, the above activities remain but, in addition, the factory is regarded as one phase of community life through which measures of value to general health may be applied. These measures may, indeed, advance productivity, but even if they do not do this directly, they are justified as means to improved community health.

We have seen how this broadening horizon has been expressed in western Europe through gradual extension of the scope of laws governing factory inspection, through the organization of voluntary societies for promotion of better in-plant medical services, and through the direct initiative of enlightened employers. The pre-employment medical examination and the periodic re-examination have become widely accepted as desirable. A special influence has been exerted by government 
beyond its supervisory role when government has become employer. Thus, in the nationalized industries of Great Britain, France, and other countries, particularly comprehensive occupational health programmes have been organized. The trend has been reflected in the work of the various research institutes in occupational health like those in Finland and Yugoslavia, where investigations are made in "industrial physiology", to determine the optimal conditions (human and environmental) for working efficiency.

The trend is also shown in the activities of international bodies. The scope of the conventions and recommendations of the International Labour Organization has significantly changed over the last 30 years. The earlier actions were devoted to promoting protective measures in particular trades or in the use of particular chemicals, like lead or phosphorus. The I.L.O. obviously reflected the interests of national ministries of labour. The more recent actions have concerned general medical examination of young persons, general labour inspection, and the safeguarding of maternity (De Boer, 1952). Under consideration now is a new proposed convention on "Protection of the Health of Workers in Places of Employment". While this instrument does not go so far as to call for the establishment of medical services and general preventive measures in plants, it calls for a wide range of preventive medical examinations. In the World Health Organization, organized in 1948, concern for occupational health has been directed toward aspects other than occupational diseases and injuries (Roemer and Da Costa, 1953).

In other continents the broadening objectives of occupational health work have taken the forms found in western Europe but, in addition, they have found another expression. This has been the increasing tendency to consider the health protection of workers as a branch of general public health work under the direct supervision of the overall public health agency. This change has served to direct attention not only to the task of eliminating occupational hazards, but to promote the general health of workers through the convenient approach of the factory-just as the child's health is promoted through the school. This shifting of official responsibility, as we have seen, is found on every continent in greater or lesser degree.

It cannot be claimed that public health agency administration of occupational health inevitably means this broad approach. In some measure the trend may be due to other reasons, such as the fact that the health ministries are the major resources for skilled personnel in social medicine. In certain instances public health administration may for the moment yield a programme no wider in scope than traditional factory inspection. What is important, however, is that public health administration provides the natural framework for a broader approach-one in which it will easily grow-since the public health agency is, by definition, devoted to advancing the total health of the community. It is less likely to have its aims limited by considerations of injury compensation laws or even the needs of productive efficiency.

\section{Conclusions and Discussion}

Developments in social medicine come in response to social needs, but the development of occupational health within public health administration can help to meet needs beyond those that have provided the immediate stimulus. One of the most pressing needs in modern public health is the development of preventive programmes for the adult population, other than maternity services. As communicable diseases are reduced, especially in childhood, the larger disease problems faced by a society tend to become the chronic, degenerative disorders of adult life : cardiovascular disease, cancer, diabetes, and arthritis, as well as mental disorders. It is difficult to tackle these afflictions on a public health basis, but one of the best approaches currently available is through assurance of early diagnosis and prompt treatment. Multiple screening tests given through the place of work are an important method of early diagnosis, and arrangements for prompt treatment can be made through an industrial medical care programme. Insofar as nutrition or personal living habits may provide a key to the prevention of arteriosclerosis, hypertension or other chronic diseases, health education through the factory may be effective. In a word, the work place can be an excellent locale for the promotion of an adult health service, both preventive and curative.

It is also important to consider the administrative relationship of occupational health and of general community health administration. The individual with his family is the common denominator to all health services, but a full understanding of their problems calls for knowledge from many different sources, and effective action requires authority in many spheres. For these reasons, sound application of both preventive and curative health services demands coordination of many different organized programmes at the local level. The local public health officer is the obvious instrument for such coordination, but this is possible for the employed adult only if this officer has authority within the 
walls of the work place. The need for unified health administration at the local level has become increasingly recognized by public health leaders throughout the world (Mackintosh, 1952). It is undoubtedly at the root of the current debates on occupational health administration in relation to the National Health Service in Great Britain. In the under-developed countries, even less can the economies support the extravagance of overlapping or uncoordinated medical-social administration.

It should be stressed that coordination of occupational health and public health services at the local level does not necessarily imply a change in authority at the national level. A Ministry of Education or Ministry of Commerce may and does delegate certain authorities to the local public health officer, and there is no reason why a Ministry of Labour cannot do the same thing.

In most countries the control of nuisances created in the community by industry, through river or atmospheric pollution, rests with the public health authorities, even when control of the internal factory environment lies with the labour authorities. In urban life, this problem can take on large proportions, and it should be more effectively handled if the agency responsible for general community sanitation has free access to the interiors of factories.

All countries possess, or are developing, a network of local health administrations to cover their entire population. These local health departments are close to the people, working with community groups on all questions affecting health. They are in an exceilent position to keep in touch with local industries in their area-not on the infrequent basis that is inevitable when a national ministry has only a handful of medical inspectors of factories distributed regionally over a large area, but frequently and regularly. In other words, the local health department can provide the community "family doctor " in close contact with the work place, to be aided by the specialist or consultant at the regional or national level when difficult technical problems arise.

This approach has special value in underdeveloped countries where the preponderance of employment is in agriculture or in small shops. The organization of small-plant occupational health services on a cooperative basis is widely recognized as the solution to a difficult problem, and the local public health staff is admirably suited to organize such services. Not that the health officer or public health nurse could render the direct clinical services required in the plants-a point on which there is sometimes misinterpretation-but they could promote and organize such programmes. The prac- ticability of this idea has been demonstrated in several communities in the United States and New Zealand, although the need is doubtless greater in less prosperous countries.

Finally, one may ask how much therapeutic medicine should properly be provided in a health programme centred at the place of work? Obviously the answer will differ in different social systems, depending on the overall national arrangement for medical care. Where most medical service is procured through independent physicians-either paid privately as in America or by insurance as in western Europe-the tendency is for in-plant health services to be limited to prevention and care of minor illnesses, while most therapy is left to the personal physician. In societies where most medical services are rendered through a public system-as in the Communist nations and in many underdeveloped and formerly colonial countries-complete medical services are often rendered through the enterprise (factory or plantation). In either case, there is a need for coordination of preventive services and therapy, if only in the interests of economy for the latter. Social security systems have recognized this need, through their efforts to promote industrial safety and hygiene programmes in most European countries. Likewise, when the health ministry has responsibility for administration of medical care programmes, its officers have a natural incentive to promote preventive health services in industry, and they have the opportunity to coordinate preventive and curative services.

If trends toward the organization of public medical services continue throughout the world, we may reach a time when most medical care will be given through health centres in each community. If this is done, such centres should be closely associated with all factories and work places, having on their staffs physicians and nurses who would be seconded to industry to provide preventive medical services and on-the-spot care in the plants. The latter services might be financed by the industry or by the government, depending on the general economic system. The important point is that the services should be coordinated, so that the physician and nurse, seeing the worker in the plant, would be in close professional touch with the physician in the health centre who treats him when he is sick. Similar coordination with the hospital is essential. Such comprehensive, integrated service for the worker and his family would only be possible if all community health services-preventive, occupational, hospital, curative care of the ambulant patient-are administered under a single direction. The public health team of today is trained in the skills of 
health administration, preventive medicine, environmental control, and social organization, which are applicable within the factory walls as well as outside them.

There is no intention here to minimize the importance of the classical activities of industrial hygiene, designed to limit the wastage caused by industrial accidents and occupational diseases. In many under-developed countries, which have hardly yet come to recognize their own industrial hazards, this is an important priority. While they are being tackled, however, the whole picture of the worker's health can be kept in mind. One should also keep in mind the need for integration of specialized services in total community health organization.

The necessity of factory inspection remains for various aspects of work which go beyond the strict sphere of health maintenance, such as legislation controlling the employment of children and women, night work, and rest periods. Likewise the general physical arrangements of production processes are important, not only for the sake of accident prevention, but also for the general comfort and morale of the worker. In some countries, the jurisdictional line between the functions of labour and health agencies has been drawn on this basis, with the labour inspectorate covering safety while the health agency covers all other aspects of health. Enforcement of standards in both spheres, however, may be vested with the labour authority.

The labour ministry may claim that there is an advantage in encompassing the problems of the "whole worker"-his wages, hours, working conditions, collective bargaining, as well as his health. The same argument has been made about the "whole child" or the "whole farmer" or the "whole military veteran"-leading to the establishment of independent, vertical health programmes for the child, the farmer, or the veteran. It is these demographic groups themselves who suffer most by isolation from the main stream of skilled professional service and community health activity. Modern medicine and public health are exacting disciplines, requiring special training and skill. Any nation, or certainly any local community, can achieve the best results by vesting responsibility for these services in a single health agency where the best professional talents are concentrated. In fact, by dispersing authorities, administrative funds are dispersed and it becomes more difficult to attract competent men and women to public health or social medicine.

In any event, energetic cooperation among all governmental authorities concerned with the health of people is essential. Exclusion of public health agencies in certain countries from the occupational health domain is not only due to laws and traditions and to a jealous guarding of prerogatives by labour authorities, but also to lack of initiative by public health agencies, failure to exploit opportunities, and rigid adherence to certain classical paths in public health. But, even without new legislation, there are numerous opportunities for health departments to render useful service to industry and to workers in epidemiological investigations, communicable disease control, sanitation, health education, and even in maternal and child health work (Abrams, 1952). Within existing legal frameworks, therefore, much can be improved, as was pointed out recently by the Joint Committee on Occupational Health of the International Labour Organization and the World Health Organization (W.H.O., 1953). As experience in cooperation is gained, laws and practices may be changed to provide the administrative foundation for completing the evolution from factory inspection to adult health service.

\section{REFERENCES}

Abrams, H. K. (1952). Occup. Hlth, 12, 23

"Annual Report of the Public Health Commissioner with the Government of India for 1946", p. 54. Government of India Press.

Belgian Congo : Direction Générale des Services Médicaux (1950). Rapport Annuel.

Bloomfield, J. J. (1938). Amer. J. publ. Hlth., 28, 1388

1948). "Industrial Hygiene Problems in Bolivia, Peru and Chile". (Publ. Hlth Bull., Wash., No. 301), p. 74.

- (1950). Industrial Hygiene Problems in Brazil. Institute of Inter-American Affairs, Washington.

1952). Recent Developments in Industrial Hygiene in Latin America. World Health Organization, Geneva.

Bousser, J., and Gillon, J. J. (1952). Int. Labour Rev., 65, 184.

Bousser, J., and Gillon, J. J. (1952). Int. Labour Re
Brown, J. (1950). J. industr. Nurses, Mchr., 2, 188.

Brown, J. (1950). J. industr. Nurses, Mchr., 2, 188.
Bruusgaard, A. (1952a). J. Irish med. Ass., 30, 32.

Bruusgaard, A. (1952a). J. Irish med. Ass., 30, 32. 952b). Occupational Hed
Organization, Geneva.

California State Department of Health (1952). “ Plan of Integration and Definition of Responsibilities of the Departments of Industrial Relations and of Public Health with Respect to the Health and Safety of Industrial Workers in California".

Canaperia, G. A. (1950). Sci. med. ital., 1, 180.

Chu, C. K. (1952) Personal communication.

Cluver, E. H. (1948). Public Health in South Africa, 5th ed., pp. 337-349. Central News Agency, South Africa.

Cummings, C. J., Smith, G., and Hadley, J. C. G. (1952). Publ. Hith, C. J., Smith,

Dale Report (1951). Report of a Committee of Enquiry on Industrial Health Services, Cmd. 8170 . H.M.S.O., London.

Dastur, H. P. (1952). Industrial Health Service in India. World Health Organization, Geneva.

Davies, I. G., Schilling, R. S. F., and Banks, A. L. (1952). J. roy. sanit. Inst., 72, 528, 534, 540 .

De Boer, H. A. (1952). Trends in Occupational Health Legislation. World Health Organization, Geneva.

Diaz, J. T. (1951). Med. Bull., N.Y., 11, 178.

Doyle, H. (1951). Reported in Industr. Hlth. Monthly, Wash., 11, 133.

Eoyle, H. (1951). (1952). Occupational Health in Argentina. World Health Organization, Geneva.

Forssman, S. (1952). Arch. industr. Hyg., 4, 597.

Goldwater, L. J. (1952). Industrial Hygiene and Occupational Medicine in Yugoslavia. World Health Organization, Geneva

International Labour Office (1951). Protection of the Health of Workers in Places of Employment, Report VIII (1), pp. 62-64. Geneva.

Japanese Ministry of Health and Welfare (1952). A Brief Report on Public Health Administration in Japan.

Klem, M. C., McKiever, M. F., and Lear, W. J. (1950). Industrial Health and Medical Programs, pp. 321-344. Public Health Service Publication No. 15. Government Printing Office Washington 
Leimena, J. (1952). The Upbuilding of Public Health in Indonesia. Ministry of Health, Indonesia.

Lewis, L. (1952). Report on Preliminary Industrial Health Survey of Iran. World Health Organization, Geneva.

Mackintosh, J. M. (1952). Chron. Wld. Hlth. Org., 6, 180, 219.

Miller, S. E. (1952). " Organization of Occupational Health Services in Small Plants". First European Seminar on Occupational Health, Leyden. World Health Organization, Geneva.

Natvig, H. (1952). " The Industrial Health Service in an Individual Country (Norway)". First European Seminar on Occupational Health, Leyden. World Health Organization, Geneva.

Newquist, M. N. (1938). Medical Service in Industry and Workmen's Compensation Laws, pp. 32-33. American College of Surgeons, Chicago.

Nigeria : Department of Medical Services (1950). Annual Report of the Medical Services for the Year 1948. Government Printer, Lagos.

Noro, L. (1951). Arch. industr. Hyg., 4, 597.

Patterson, W. B. (1950). Industr. Med. Surg., 19, 343.

Petrie, L. M. (1952). Health Problems of Industrially Employed People in Turkey. World Health Organization, Geneva.
Philippine Republic: Department of Health (1952). Annual Report of the Secretary of Health 1950-51. Manila.

Roemer, M. I. (1948). Industr. Hyg. Newslett., 8, No. 9 (Sept.), p. 6. Sigerist and Da Costa, O. L. (1953). Arch. industr. Hyg., 7, In Union. Citadel Press, New York.

Tabershaw, I. R (1951). Arch, industr. Hyg. 3, 298.

Teleky, L. (1948). History of Factory and Mine Hygiene, pp. 3-74. Columbia University Press, New York.

Travail et Securité, Paris (1950), 2, 159 . "La Prévention des Accidents et la Protection de la Santé des Travailleurs en U.R.S.S."

Trasko, V. M. (1950). Industrial Health Legislation: A Compilation of State Laws and Regulations. U.S. Public Health Service, Washington.

World Health Organization (1951). "Public Health Services in Belgium " (1951). Travelling Study Group on Public Health Administration in Europe. Geneva.

- (1952). "Information on Occupational Health in Some European Countries" (1952). First European Seminar on European Countries" (1952). First Euro

Occupational Health, Leyden. Geneva.
- (1953). Joint Committee on Occupational Health of the International Labour Organization and the World Health Organization (1953). Report of Second Session. Geneva. 